\title{
FURTHER EXAMINATION OF YOUTH LEADERSHIP SKILLS PREDICTORS
}

\section{Abstract}

Considering the substantial upcoming transfer of leadership to younger generations, it is critical to study the unique trait, skill, and behavioral associations of youth leaders. The purpose of this two-phase study was to quantitatively examine the relationship between positive psychological capacities (PsyCap), personality, and empathy with leadership skills in youth. Regression results from both phases revealed cognitive empathy and academic PsyCap as significant predictors of youth leadership life skills. These results follow earlier research that identified trait-based emotional intelligence as a significant predictor of leadership skills in youth. The combined results offer important considerations as leadership scholars and practitioners attempt to accurately predict and plan for the leadership transfer landscape over the next two decades. These combined results also serve as helpful considerations for youth leadership practitioners as program outcomes, learning objectives, and activities targeting the development of cognitive empathy and PsyCap will perhaps allow for more productive youth leadership development efforts and better documentation of their impact.

\section{Introduction}

The United States is predicted to experience one of the largest transfers of leadership in its history as evidenced by individuals 45 years of age or older currently holding $55 \%$ of all management occupations in the United States workforce (U.S. Bureau of Labor Statistics, 2017). This statistic signifies that over half of all management occupations will be transferred to a younger generation within the next 20 years. As a result, many young adults will likely assume leadership roles early in their career, thus necessitating the need for earlier leadership development experiences. Reichard and Paik (2011) argue that youth are more malleable than adults and can demonstrate greater impact from intentional leadership development. Additionally, Lord, Hall, and Halpin (2011) report significant linkages between adult leadership and childhood experiences. Many communities also recognize the need to prepare youth leaders for the future as a 2012 Midwestern rural poll revealed $61 \%$ of respondents listing "training young residents in the community for leadership roles" as very important (Center for Applied Rural Innovation, 2012, p. II-III). The capacity of youth to experience leadership development, the necessity of that development, and the recognition that youth leaders can be active contributors to their schools, families, and communities provide meaning to the present study.

The purpose of this two-phase study was to quantitatively examine the relationship between positive psychological capital, personality, and empathy with leadership skills in youth. The first 
phase examined empathy and positive psychological capital (PsyCap; hope, efficacy, resilience, and optimism, Luthans, Youssef, \& Avolio, 2007) as predictors of youth leadership skills, hypothesizing that youth who demonstrate higher levels of empathy and positive psychological capital will perceive themselves as having higher leadership skills. The second phase examined both trait-like (personality) and state-like characteristics (PsyCap), hypothesizing that a developmental construct (like PsyCap) can predict youth leadership skills beyond trait-like characteristics.

Upcoming generations of young leaders may or may not demonstrate the same trait, skill, and behavioral leadership associations as older generations of leaders. Leadership scholars and practitioners would be prudent to study the unique associations of youth leaders so as to more accurately predict and plan for the leadership transfer landscape over the next two decades. Additionally, understanding self-perception of leadership in youth is critical as it provides a window into leadership identity. Murphy and Johnson (2011) identified leadership identity and self-regulation as the two most frequently cited results of leadership development (e.g., Gardner, Avolio, Luthans, May, \& Walumbwa, 2005), which are strongly associated with leadership effectiveness (Avolio \& Hannah, 2008). Lord et al. (2011) advocate for the role of identity in leadership, arguing that identities develop over a lifetime and reveal connections from adult leadership to childhood experiences. The combined results from the present study will serve as useful considerations for youth leadership practitioners as program outcomes, learning objectives, and activities targeting the development of constructs presented in this study will allow for more productive leadership development efforts and better documentation of their impact. Graduates of such youth leadership development efforts, when asked to assume early career leadership roles as young adults, will perhaps be better prepared to demonstrate leadership effectiveness in a leadership transfer environment.

\section{Summary of Recent Literature}

The present two-phase study builds from McElravy and Hastings' (2014) initial research that examined the relationship between personality, trait-based emotional intelligence, and self-perceived leadership skills in youth. Regression results of McElravy and Hastings' study identified trait-based emotional intelligence as the strongest predictor of selfperceived leadership skills in youth, however, limitations associated with the emotional intelligence construct requires a re-investigation of leadership skill predictors in youth. The subsections below begin with a more detailed description of McElravy and Hastings' (2014) study to provide a clearer context within which the present two-phase study's findings offer a unique contribution. The literature review concludes by summarizing the recent literature on the constructs examined in the present two-phase study, namely personality, empathy, and psychological capital (PsyCap).

Results of Previous Study and Emotional Intelligence. McElravy and Hastings' (2014) study examined the relationship between traits, including the Big-Five model of personality and emotional intelligence (EI), and self-perceived leadership skills in 115 youth participating in summer leadership conferences, ranging in age from sixth grade to 12th grade. El is generally defined as "the set of abilities (verbal and non-verbal) that enable a person to generate, recognize, express, understand, and evaluate their own and others' emotions in order to guide thinking and action that successfully cope with environmental demands and pressures" (Van Rooy \& Viswesvaran, 2004, p. 72). Multiple regression results from the McElravy and Hastings (2014) study indicated that personality, measured using the fivefactor model of personality (John, Naumann, \& Soto, 2008; John, Donahue, \& Kentle, 1991; Benet-Martinez 
\& John, 1998), did not predict additional variance above trait-based emotional intelligence in self-perceived leadership skills. The model including all variables (age, gender, race/ethnicity, socioeconomic status, extraversion, agreeableness, conscientiousness, neuroticism, openness, and emotional intelligence) explained 35.3\% (Adjusted R2; $F=5.77, p<0.01$ ) of the variance in self-perceived leadership skills among the surveyed youth; however, age and emotional intelligence emerged as the only significant predictors of self-perceived leadership skills. Additionally, emotional intelligence explained over four times the amount of variance in self-perceived leadership skills than age. Soto, John, Gosling, and Potter's (2011) comprehensive examination of age trends in personality research may offer insight to this finding as distinct and profound trends in personality across late childhood and adolescence as compared to adulthood trends were revealed. Considering the potentially confounding influence of age on personality, the present two-phase study narrows the analysis on one age group as opposed to adolescents ranging in age from sixth grade to 12 th grade.

Additionally, despite the evidence from previous work linking emotional intelligence (EI) to leadership (Harms \& Credé, 2010; McElravy \& Hastings, 2014; Moore \& Rudd 2004, 2005), recent research suggests that $\mathrm{El}$ and Big Five personality traits are perhaps synonymous (van der Linden et al., 2017). A recent $\mathrm{El}$ meta-analysis (Joseph, Jin, Newman, \& O'Boyle, 2015) called in to question the construct validity of mixed El measures given their strong association with other psychological constructs, such as ability-based El, self-efficacy, conscientiousness, and general mental ability (multiple $\mathrm{R}=.79$ ) and offered an updated estimate of the meta-analytic correlation between mixed $\mathrm{El}$ and supervisor-rated job performance $(\mathrm{p}=$ .29) as well as a non-significant predictive relationship between mixed $\mathrm{El}$ and job performance $(\mathrm{B}=-.02)$ after controlling for its overlap with other constructs. In light of these findings, exploring predictors of youth leadership was completed in the present study without assessing $\mathrm{El}$, as the specificity associated with measuring discrete trait-like characteristics (e.g.,
Big Five traits), state-like characteristics (PsyCap), ability-based constructs (e.g., cognitive empathy), and leadership skills would potentially provide a more nuanced picture.

Personality. Trait leadership examines innate characteristics, such as personality, and their relationship to leadership, arguing that some traits are common among effective leaders (Yukl, 2010). Judge, Bono, Ilies, and Gerhardt (2002) conducted a meta-analysis examining the relationship between personality and leadership. Using the five-factor model of personality, a model describing five broad dimensions of personality (Big Five: extraversion, agreeableness, conscientiousness, neuroticism, and openness to experience) and two leadership criteria (leadership emergence and leader effectiveness), meta-analytic results indicated a statistically significant multiple correlation of .48 between personality and leadership. Extraversion exhibited the strongest and most consistent association with leadership, even after controlling for other personality factors. Conscientiousness and openness to experience demonstrated the next highest associations with leadership, with conscientiousness emerging as the strongest predictor of leadership in the multivariate analysis.

Among student populations, Judge et al. (2002) reported significant associations between all five personality factors and varying leadership criteria at the 95\% confidence interval (Neuroticism -.27, Extraversion .40, Openness to Experience .28, Agreeableness .18, Conscientiousness .36). Student studies included in Judge et al's meta-analysis ranged from assessing the personality of student leaders (in comparison to non-leaders; e.g. Flemming, 1935; George \& Abraham, 1966; Hunter \& Jordan, 1939; Karnes \& McGinnis, 1996; Kureshi \& Fatima, 1984; McCullough, Ashbridge, \& Pegg, 1994; Sinha \& Kumar, 1966) to investigating adult-determined leadership characteristics in youth (e.g. Landau \& Weissler, 1990) to more traditional analyses of the relationship between personality and leadership skills (e.g. Karnes \& D'llio, 1990). The vast age differences among the student populations studied (ranging 
from elementary-age to college-age students) should be noted however, along with the wide array of years spanned (ranging from the 1930s to the late 1990s) and the inconsistent measure of leadership as a dependent variable.

Several personality studies among youth and young adult leaders used the Myers Briggs Type Indicator (MBTI; Darst, 1998; Owings \& Nelson, 1979; Wingenbach, 2000). The MBTI is designed to specify a respondent's preference on each of four basic personality traits: (a) extroversion or introversion, (b) sensing or intuition, (c) thinking or feeling, and (d) judging or perceiving (Jung, 1971). Overall, findings among youth and young adult populations were mixed and inconclusive relative to the trait associations with leadership as measured by the MBTI. Although the MBTI is used often in training (Luthans, 2011), after reviewing $\mathrm{MBTI}$ research, Gardner and Martinko (1996) concluded that many findings should be considered suspect because of their inconsistencies across studies. Additionally, since the psychometrics of the MBTI have been called into question (Barbuto, 1997; Boyle, 1995; McCrae \& Costa, 1989; Pittenger, 2005), the present study focused only on the Big Five.

Cognitive and Affective Empathy. Empathy, as a dispositional characteristic, is articulated as "the ability to comprehend another's feelings and to reexperience them oneself" (Salovey \& Mayer, 1990, p. 194). Several strands of research and reviews have linked empathy with effective leadership (Cooper \& Sawaf, 1997; Gooty, Connelly, Griffith, \& Gupta, 2010; Kellett, Humphrey, \& Sleeth, 2002; Kellett, Humphrey, \& Sleeth, 2006; Wolff, Pescosolido, \& Druskat, 2002; Yukl, 2010). Kellett et al. (2002) developed a model proposing empathy as one of two behavioral paths influencing perception of leadership. Structural equation modeling results from 168 organizational behavior students demonstrated good model fit and support for the proposed relationship between displaying empathy and perceived leadership. Kellett et al.'s 2006 study offered similar findings among 198 undergraduate and 33 graduate workgroup peers. While controlling for cognitive ability and complex task performance, structural equation modeling of the relationship between empathy and attributions of task and relational leadership revealed strong model fit and significant standardized path coefficients. Wolff et al. (2002) developed a model hypothesizing an indirect relationship between empathy and task leadership arguing that empathy precedes and enables the necessary cognitive skills (pattern recognition and perspective taking) for task leadership, which was supported from structural equation modeling results among $382 \mathrm{MBA}$ students in 48 self-managed teams. Among student populations, high cognitive and affective empathy resulted in higher ratings of prosocial behavior (Roberts \& Strayer, 1996).

Joliffe and Farrington (2006) have been two of the more major contemporary scholars examining empathy in adolescent populations. In their development and validation of a basic empathy scale, their factor analysis verified two factors that measure the empathy construct: Cognitive empathy and affective empathy. Cognitive empathy is considered an ability-based construct, describing the extent to which one can understand the emotions of another, while affective empathy is a construct that demonstrates affective congruence, the degree to which someone shares in another's emotional state (Joliffe \& Farrington, 2006).

In testing their scale, Joliffe and Farrington (2011) examined the relationship between empathy and bullying among 720 adolescents in three England secondary schools. Stepwise logistic regression results indicated that only low affective empathy was independently predictive of bullying in males, but not females. Low cognitive empathy did not demonstrate a significant predictive relationship to bullying. Results from Ang and Goh's (2010) hierarchical multiple regression analyses of 396 adolescents from singapore revealed somewhat similar results, in that, students (both male and female) who demonstrated low cognitive and low affective empathy had higher cyberbullying scores. Chow, Ruhl, and Buhrmester (2013) investigated the relationship between adolescents' empathy and friendship quality among 146 same-sex friendship 
dyads in the 10th grade. Structural equation modeling results indicated a positive and predictive relationship between empathy and friendship quality that was mediated by interpersonal competencies, namely intimacy and conflict management. While indirectly related to leadership, empathy research in adolescents seems to converge on the idea that high displays of empathy are associated with positive and prosocial behaviors while low levels of empathy are related to negative and destructive behaviors, such as bullying.

Psychological Capital. Given that personality traits, trait-based emotional intelligence, and affective empathy constructs are relatively stable over time, psychological capital (PsyCap)-a developmental construct-provides a unique avenue for empirical examination. PsyCap is a higher-order, core construct comprised of four lower-order constructs, namely hope, efficacy, resiliency, and optimism (Luthans, Youssef, \& Avolio, 2007). Furthermore, PsyCap is a state-like, developmental, construct defined as "one's positive appraisal of circumstances and probability for success based on motivated effort and perseverance" (Luthans et al., 2007, p. 550). A growing amount of evidence has linked PsyCap to effective leadership (Avey, Avolio, \& Luthans, 2011; Clapp-Smith, Vogelgesang, \& Avey, 2009; Rego, Sousa, Marques, \& Cunha, 2012) and positive outcomes in adults (e.g. psychological well-being and workplace performance; see meta-analysis conducted by Avey, Reichard, Luthans, \& Mhater, 2011). For example, Avey, Avolio, and Luthans (2011) empirically analyzed the impact of leader positivity on follower positivity and performance. Data results from this randomized experiment among 106 engineers from a large aerospace firm revealed a positive relationship between the leaders' positivity (as measured by PsyCap) and follower positivity (as measured by PsyCap) and performance. Avey et al. concluded that leaders' PsyCap first impacts followers' PsyCap, which subsequently impacts follower performance. While PsyCap has been linked to positive leadership and positive outcomes among adult populations, little research has investigated PsyCap in youth populations.

\section{Methodology}

Recall that the present two-phase study follows McElravy and Hastings' (2014) study that examined personality and trait-based emotional intelligence (EI) as predictors of youth leadership life skills, revealing trait-based $\mathrm{El}$ as a significant predictor. Considering the findings of the most recent El metaanalysis (Joseph, Jin, Newman, \& O'Boyle, 2015) which called in to question the construct validity of mixed El measures, predictors of youth leadership was examined in the present study without assessing El, as the specificity associated with measuring discrete trait-like characteristics (e.g., Big Five traits), state-like characteristics (e.g., PsyCap), ability-based constructs (e.g., cognitive empathy), and leadership skills would potentially provide a more nuanced picture.

Thus, the purpose of the first phase was to examine empathy (both a trait- and ability-based construct) as well as the state-like characteristic of positive psychological capital (PsyCap; hope, efficacy, resilience, and optimism, Luthans, Youssef, \& Avolio, 2007) as predictors of youth leadership skills, hypothesizing that youth who demonstrate higher levels of empathy and positive psychological capital will perceive themselves as having higher leadership skills. The second phase examined both trait-like (personality) and state-like characteristics (positive psychological capital), hypothesizing that a developmental construct (like PsyCap) can predict youth leadership skills beyond trait-like characteristics.

Both phases of the present study utilized regression because the intent of the analysis was to examine the predictive relationship between positive psychological capacities (PsyCap), personality, and empathy with leadership skills in youth. Additionally, the intent of the present study was to generalize information obtained from the sample to the larger population of youth leaders; thus, statistical inference was key.

Sampling Procedure. Recall that trait-based 
emotional intelligence explained over four times the amount of variance in self-perceived leadership skills than age in McElravy and Hastings' (2014) study. Considering the results of Soto, John, Gosling, and Potter's (2011) comprehensive examination of age trends in personality revealing distinct and profound personality trends across late childhood and adolescence, the present two-phase study narrowed its analysis on one age group as opposed to adolescents ranging in age from sixth grade to 12th grade. Thus, the participants for the present twophase study were incoming sixth-grade students who had been identified by their school's administrators and teachers as having leadership potential and selected for a summer youth leadership development program offered by a local university in 2013 and 2014.

Data Collection and Analysis. For the first phase, the Basic Empathy Scale (Joliffe \& Farrington, 2006), the implicit PsyCap (Harms \& Luthans, 2012) measure, a demographic form, and the Youth Leadership Life Skills Development scale (YLLSDS; Seevers, Dormody, \& Clason, 1995) were administered to the incoming sixth-grade students who had been selected for the aforementioned youth leadership development program in summer, 2013. Sixty-four of the approximate 90 student participants consented and voluntarily completed the survey packets onsite at the program during the summer, 2013. To address the potential for common-method variance, student participants completed the measures for the predictor and criterion variables on different days as recommended by Podsakoff, MacKenzie, Lee, and Podsakoff (2003). Thirty-eight students submitted complete data (Mage $=10.87$; SDage $=.34 ; 53 \%$ female). To test the predictive value of cognitive and affective empathy and psychological capital on self-perceived leadership skills in youth, the authors conducted a regression analysis using SPSS.

For the second phase, the Big Five Inventory (BFl; John, Naumann, \& Soto, 2008; John, Donahue, \& Kentle, 1991; Benet-Martinez \& John, 1998), the implicit PsyCap measure (Harms \& Luthans, 2012), the academic PsyCap measure (Luthans, Luthans, \&
Avey, 2014; Luthans, Luthans, \& Jensen, 2012), the Basic Empathy Scale (Joliffe \& Farrington, 2006), a demographic form, and the Youth Leadership Life Skills Development scale (YLLSDS; Seevers, Dormody, \& Clason, 1995) were administered to incoming sixth-grade students who had been selected to attend the aforementioned youth leadership development program in summer, 2014. Sixty-seven of the approximate 90 selected student participants consented and voluntarily completed the survey packets on-site at the program during summer, 2014. Again, student participants completed the measures for the predictor and criterion variables on different days to address common-method variance, following Podsakoff et al.'s (2003) recommendation. Forty students submitted complete data (Mage $=10.91$; SDage $=.43 ; 59 \%$ female). To test the predictive value of personality, empathy, and psychological capital on self-perceived leadership skills in youth and to test the hypothesis that a developmental construct (like PsyCap) can predict youth leadership skills beyond trait-like characteristics, a stepwise regression analysis was conducted using SPSS.

Scales Used.

Personality. The Big Five Inventory (BFl; John, Naumann, \& Soto, 2008; John, Donahue, \& Kentle, 1991; Benet-Martinez \& John, 1998) is designed to measure the five-factor model of personality: extraversion, neuroticism, openness to experience, agreeableness, and conscientiousness. The BFI contains 44 short items where participants rate their agreement with each item statement on a 5-point scale, from 1 (disagree completely) to 5 (agree completely). Table 1 offers example items from the five factors. 
Table 1.

The BFI Factors and Example Items

\begin{tabular}{|c|c|}
\hline BFI Factors & Example items \\
\hline Extraversion & Generates a lot of enthusiasm. Tends to be quiet (R). \\
\hline Agreeableness & Is generally trusting. Is sometimes rude to others (R). \\
\hline Conscientiousness & Tends to be disorganized (R). Keeps working until things are done. \\
\hline Neuroticism & Is relaxed, handles stress well (R). Worries a lot. \\
\hline Openness & $\begin{array}{l}\text { Likes work that in the same every time (R). Likes to think and play } \\
\text { with ideas. }\end{array}$ \\
\hline
\end{tabular}

*Note. Reverse-keyed items are denoted by (R). The common stem for all BFl items is "I see myself as someone who ..."

$\mathrm{BFI}=$ Big Five Inventory.

John, Naumann, and Soto (2008) reported high convergence of the BFI measure with the most common personality measures, namely the NEO Five-Factor Inventory (NEO-FFl; Costa \& McCrae, 1992) and Goldberg's Trait Descriptive Adjectives (TDA; Goldberg, 1992; Saucier, 1994). Mean standardized convergent validity coefficients reported were .95 for the BFI and TDA and .93 for the BFI and NEOFFI. The BFI is written at a fifth-grade reading level (Benet-Martinez \& John, 1998), and strong internal consistency has been demonstrated with youth samples as young as 10 years old (Soto, John, Gosling, \& Potter, 2008, 2011). Thus, the $\mathrm{BFI}$ was used in the present study due to the sample population age, the reported convergent validity with the most well researched personality measures, and the short completion time requirement of approximately 15 minutes.

Demographics. Following Van Linden and Fertman's (1998) suggestion, three demographic variables were included as control variables for both phases: gender, race/ethnicity, and socioeconomic status (SES). Additionally, age was controlled by narrowing the analysis to incoming sixth graders. To collect information on SES, the Barratt Simplified Measure of SocioEconomic Status (Barratt, 2012), based on the work of Hollingshead (1957, 1975), was used. Respondents indicate education level of both parents on a 7-point scale, from "Less than 7th Grade" to "Graduate Degree." Respondents also indicate their parents' occupation, which is broken into nine groups. Examples of group one occupations include "day laborer and busboy," whereas examples of group nine occupations include "physician and accountant." The calculated parental education and occupation scale averages are combined to generate a rating of SES ranging from 2 to 16 , which can be treated as a continuous variable in a regression analysis (Barratt, 2012).

Empathy. The Basic Empathy Scale (BES; Joliffe \& Farrington, 2006) is a 20-item scale designed for adolescents that measures both cognitive and affective empathy. Respondents are asked to respond on a Likert scale from 1 (strongly disagree) to 5 (strongly agree) to items such as, "I get caught up in other people's 
feelings easily" (affective) and "I can often understand how people are feeling even before they tell me" (cognitive). Confirmatory factor analysis results indicated goodness of fit with a two-factor model of empathy, with all but one item demonstrating a significant factor loading. Affective empathy and cognitive empathy demonstrated significant overlap $(r=.41$ for males, $r=.43$ for females), yet also discrimination. BES scores demonstrated appropriate convergent validity through positive associations with other empathy scales ( $r=.53$ for males, $r=.43$ for females), intelligence (females only), prosocial behavior, and personality (agreeableness and openness), and the BES demonstrated appropriate divergent validity through negative associations with alexithymia (inability to identify and describe emotions in the self) and a nonsignificant relationship with social desirability. The use of the BES has demonstrated strong internal reliability, with Cronbach alpha $=$ .75 for the cognitive subscale and .76 for the affective subscale (Ang \& Goh, 2010).

Positive Psychological Capital. As with measures of self-efficacy (Bandura, 2006), PsyCap has been developed in several different domains (e.g. academic, Luthans, B. et al., 2014; cross-cultural, Dollwet \& Reichard, 2014; leader development, Pitichat, Reichard, Kae-Edwards, Middleton, \& Norman, 2018). Within this study, an academic-based domain was implemented given that the sample population would likely be the most universal and relevant. Example items include: "There are lots of ways around any problem concerning my schoolwork" (hope); "I feel confident setting targets/ goals for my schoolwork" (efficacy); "I usually manage difficulties one way or another concerning my schoolwork" (resilience); and "I always look on the bright side of things regarding my schoolwork" (optimism). The items are rated on a 6-point scale from strongly disagree (1) to strongly agree (6). In previous studies employing academic PsyCap, generally acceptable Cronbach alphas were reported for reliability (Luthans, B. et al., 2012, Cronbach alpha $=.90$; Luthans, B. et al., 2014, Cronbach alphas ranging from .89 to .90). In order to reduce the risk of social desirability, an implicit measure of PsyCap (I-PCQ; Harms \& Luthans, 2012) was also used focused on an academic setting. The I-PCQ begins with a prompt to invent a story about someone based on a statement (e.g. someone talks to their teacher), and after reflecting, respondents are asked to rate the degree to which the character of the story feels or thinks: believing that they can accomplish their goal (hope), expecting good things to happen in the future (optimism), believing that they can bounce back from any setbacks that have occurred (resilience), and feeling confident and self-assured in their ability (efficacy). The measure consists of three story prompts followed by the eight statements (the four statements used to assess PsyCap and four filler statements) about the character. For a full psychometric review and instructions for implementing the I-PCQ, see Harms, Krasikova, and Luthans (2018).

Youth Leadership Life Skills Development Scale (YLLSDS). The YLLSDS is a measure of youth leadership skill development (Seevers, Dormody, \& Clason, 1995) and has been administered among youth as young as 12 years old (Seevers \& Dormody, 1994). Respondents indicate the degree to which they possess each skill on items such as "Can listen effectively," "Consider the needs of others," "Can select alternatives," "Can be flexible," "Can clarify my values," and "Trust other 
people from 0 (none) to 3 (high). Seevers et al. (1995) and Smith, Genry, and Ketring (2005) reported strong internal consistency with the YLLSDs (Cronbach a $=.98$ and .93 respectively) among multiple samples.

\section{Results}

For the first phase, Cronbach alpha reliabilities for the variables of interest were above the traditional cutoff score of .70 (Nunnally, 1978). The scale means, standard deviations, Cronbach alphas, and correlations between variables are provided in Table 2. The relationships between each of the control variables and variables of interest were tested first. Comparison of group mean differences in YLLSDS scores and reported gender (mean difference =
$-3.76,95 \% \mathrm{Cl},-9.13$ to $1.61, \mathrm{p}=.16)$ did not indicate a significant difference between groups, so gender was not included in the regression analysis. Six groups were created for race and ethnicity (American Indian/ Alaskan Native; Asian or Pacific Islander; Black, African American - not of Hispanic origin; White - not of Hispanic origin; Hispanic, Latino, or Spanish Origin; and Other); however, some of the groups did not have enough participants to complete an analysis of variance, so the participants were grouped as either white $(n=34)$ or minority $(n=8)$. The comparison of mean YLLSDS scores and the grouped race and ethnicity variable did not reveal a significant difference (mean difference $=1.13,95 \% \mathrm{Cl},-10.06$ to 12.32, $\mathrm{p}=.82$ ). Furthermore, correlational analyses did not indicate a significant association between SES and YLLSDS ( $r=.05, \mathrm{n}=38, \mathrm{p}=.75)$. Thus, SES and the grouped race and ethnicity variable were also not included in the regression model.

Table 2.

Correlations and Cronbach Alphas for First Phase

\begin{tabular}{|c|c|c|c|c|c|c|c|}
\hline Variable & $M$ & $S D$ & 1 & 2. & 3. & 4. & 5. \\
\hline 1. YLLSDS & 77.55 & 8.63 & $(.91)$ & & & & \\
\hline 2. SES & 12.97 & 2.39 & .05 & $n / a$ & & & \\
\hline 3. I-PsyCap & 62.45 & 10.68 & .14 & .02 & $(.71)$ & & \\
\hline 4. Emp-C & 37.24 & 4.39 & $.51 * *$ & .10 & .22 & $(.76)$ & \\
\hline 5. Emp-A & 38.55 & 6.29 & .16 & .27 & .11 & $.51 * *$ & $(.77)$ \\
\hline
\end{tabular}

Only variables that demonstrated a leadership skills among the youth surveyed with cognitive significant correlation with YLLSDS were empathy serving as a significant predictor $(\beta=.51, t=3.51$, included in the regression model; thus, $\mathrm{p}=.001$ ). PsyCap was measured in the first phase using an cognitive empathy was the only variable included implicit measure; thus, for the second phase, both the in the regression model $(\mathrm{r}=.51, \mathrm{n}=38, \mathrm{p}<.01)$. implicit and academic PsyCap measures were The regression model including cognitive empathy administered. accounted for 23.4\% (Adjusted R2; $F(1,36)=12.32, p$ $<.01)$ of the variance in self-perceived 
For the second phase, Cronbach alpha reliabilities for the variables of interest were at or above the traditional cutoff score of .70 (Nunnally, 1978) with one exception. The Cronbach alphas and correlations between variables are provided in Table 3, and the Cronbach alpha for cognitive empathy was 69 .
Given that including cognitive empathy in the phase two analysis would provide a better opportunity to replicate the findings from phase one, and given that the reliability was marginally different from the recommended cutoff of .70 , the variable was included in the analysis.

Table 3 .

Correlations and Cronbach Alphas for Second Phase

\begin{tabular}{|c|c|c|c|c|c|c|c|c|c|c|c|c|c|}
\hline Variable & $M$ & $S D$ & 1. & 2. & 3. & 4. & 5. & 6. & 7. & 8. & 9 & 10. & 11. \\
\hline 1. YLLSDS & 78.79 & 7.86 & $(.89)$ & & & & & & & & & & \\
\hline 2. SES & 12.34 & 2.47 & .26 & $n / a$ & & & & & & & & & \\
\hline 3. PsyCap & 116.19 & 11.11 & $.60^{\text {** } *}$ & .20 & $(.83)$ & & & & & & & & \\
\hline 4. I-PsyCap & 31.12 & 10.93 & -.05 & .00 & -.04 & $(.73)$ & & & & & & & \\
\hline 5. BFI-E & 30.46 & 5.83 & .11 & -.12 & $.32 *$ & .15 & $(.84)$ & & & & & & \\
\hline 6. BFI-A & 35.56 & 4.61 & $.38^{* * *}$ & $.37 *$ & $.44^{* * *}$ & .05 & .00 & $(.70)$ & & & & & \\
\hline 7. BFI-C & 35.86 & 4.60 & $.33^{*}$ & .12 & $.43^{* * *}$ & .14 & $.31^{*}$ & $.54^{\mathrm{k*} *}$ & $(.70)$ & & & & \\
\hline 8. BFI-O & 41.64 & 5.22 & $.28^{*}$ & .16 & $.40^{* * *}$ & -.06 & $.41^{* * *}$ & .26 & .22 & $(.77)$ & & & \\
\hline 9. BFI-N & 19.72 & 5.07 & -.25 & .09 & -.19 & -.19 & $-.30 *$ & $-.35^{* k}$ & $-.52 * *$ & .03 & $(.78)$ & & \\
\hline 10. Emp-C & 37.66 & 3.67 & $.21^{*}$ & -.12 & $.30^{*}$ & -.15 & .13 & .05 & .12 & .19 & -.04 & $(.69)$ & \\
\hline 11. Emp-A & 36.70 & 5.95 & -.18 & .02 & .04 & .04 & .25 & -.07 & .05 & $.32^{*}$ & .17 & $.32^{*}$ & (.73) \\
\hline
\end{tabular}

Emp-C $=$ cognitive $\mathrm{e}$
${ }^{*} p<.05 .{ }^{*} p<.01$

Comparison of group mean differences in YLLSDS scores and reported gender (mean difference = 2.16, $95 \% \mathrm{Cl},-2.05$ to $6.36, \mathrm{p}=.31$ ) did not indicate a significant difference between groups, so gender was not included in the stepwise regression analysis. Again, six groups were created for race and ethnicity (American Indian/Alaskan Native; Asian or Pacific Islander; Black, African American - not of Hispanic origin; White - not of Hispanic origin; Hispanic, Latino, or Spanish Origin; and Other); however, some of the groups did not have enough participants to complete an analysis of variance, so the participants were grouped as either white $(n=47)$ or minority ( $n$ $=9$ ). The comparison of mean YLLSDS scores and the grouped race and ethnicity variable also did not reveal a significant difference (mean difference $=5.12,95 \% \mathrm{Cl},-.22$ to $10.46, \mathrm{p}=.06$ ). Furthermore, correlational analyses did not reveal a significant relationship between SES and YLLSDS $(r=.26, \mathrm{n}=$ 54, $p=.054)$. Thus, SES and the grouped race and ethnicity variable were not included in the stepwise regression analysis.

Only variables that demonstrated a significant correlation with YLLSDS were included in the model; thus, academic PsyCap $(r=.60, \mathrm{n}=53, \mathrm{p}<.001)$, agreeableness $(r=.40, n=49, p<.01$, conscientiousness $(r=.33, n=51, p<.05)$, and openness $(r=.28, n=56, p$ $<.05)$ were entered in a stepwise regression analysis. Considering the documented association between 
personality and leadership (Judge et al., 2002), Big Five factors agreeableness, conscientiousness, and openness were entered first. Agreeableness, conscientiousness, and openness accounted for $13.0 \%$ (Adjusted R2; $F(3,36)=2.95, p<.05$ ) of the variance in self-perceived leadership skills among youth surveyed. In step 2, academic PsyCap explained $21 \%$ (R2 Change) more of the variance in self-perceived leadership skills among youth surveyed than personality. The final model including academic PsyCap and Big Five factors agreeableness, conscientiousness, and openness accounted for $33.8 \%$ (Adjusted R2; $F(1,35)=12.31, p<.01$ ) of the variance in self-perceived leadership skills among the youth surveyed. However, academic PsyCap was the only significant predictor $(\beta=.54 ; \mathrm{t}=3.51 ; \mathrm{p}<.01)$. The regression models are provided in Table 4.

Table 4.

Regression Models for Second Phase

\begin{tabular}{cccccc}
\hline Model & $\begin{array}{c}\text { Standardized } \\
\text { Beta }\end{array}$ & $\begin{array}{c}\text { Beta } \\
\text { Significance }\end{array}$ & $\begin{array}{c}\text { Adjusted } \\
\text { Model R }\end{array}$ & $\begin{array}{c}\text { Model R } \mathrm{R}^{2} \\
\text { Change }\end{array}$ & $\begin{array}{c}\text { Model R } \\
\text { Change } \\
\text { Significance }\end{array}$ \\
\hline Step One & & & .130 & .130 & .046 \\
Agreeableness & .397 & .033 & & & \\
Conscientiousness & .115 & .522 & & & \\
Openness & -.069 & .677 & .338 & .209 & .001 \\
Step Two & & & & & \\
Agreeableness & .229 & .170 & & & \\
Conscientiousness & -.001 & .997 & & & \\
Openness & -.148 & .311 & & & \\
PsyCap & .541 & .001 & & & \\
\hline Note: $N=40 ;$ PsyCap = academic psychological capital. & & &
\end{tabular}

\section{Discussion}

Summary of Results. The results of the present two-phase study suggest that youth leaders who demonstrate cognitive empathy and the positive and developmental state of high self-efficacy, hope, optimism, and resiliency perceive themselves as having high leadership skills. These results confirmed the hypothesis that youth who demonstrate higher levels of empathy and positive psychological capital will perceive themselves as having higher leadership skills. In comparison to more trait-like constructs like personality and affective empathy, which tend to be stable over time (Judge et al., 2002; Joliffe \& Farrington, 2006), cognitive empathy is considered an ability-based construct (Joliffe \& Farrington, 2006) and PsyCap is a relatively more state-like construct that can be developed with short trainings (Luthans, Avey, \& Patera, 2008). Thus, the results identifying cognitive empathy and PsyCap as significant predictors of youth leadership skills provide evidence to the notion that developmental constructs can predict youth leadership skills. The results of the second phase, specifically, where academic PsyCap contributed significantly to the model above and beyond personality and emerged as the only significant predictor of leadership skills among the youth surveyed confirmed the hypothesis that developmental constructs (like PsyCap) can predict youth leadership skills beyond trait-like characteristics.

Theoretical Implications. While several strands of research and reviews have linked empathy with effective leadership (Cooper \& Sawaf, 1997; Gooty, Connelly, Griffith, \& Gupta, 2010; Kellett, Humphrey, 
\& Sleeth, 2006; Wolff, Pescosolido, \& Druskat, 2002; Yukl, 2010), the vast majority of the research linking empathy with leadership has been among adult populations. Empathy research in adolescents has primarily identified empathy's association with positive and prosocial behaviors (Ang \& Goh, 2010; Chow et al., 2013; Joliffe \& Farrington, 2006; Joliffe \& Farrington, 2011; Roberts \& Strayer, 1996). The results of the present study identifying cognitive empathy as a significant predictor of leadership skills in youth expands literature in the field by extending empathy's association with leadership among youth populations as well as extending empathy's association in adolescence with constructs beyond just positive and prosocial behaviors.

While PsyCap has a documented association with effective leadership (Avey et al., 2011; Clapp-Smith et al., 2009; Rego et al., 2012) and positive outcomes (e.g. psychological well-being and workplace performance; Avey et al., 2011) among adult populations, little research has investigated PsyCap in youth populations. The results of the present study identifying academic PsyCap as a significant predictor of leadership skills in youth contributes to existing literature by expanding PsyCap's positive linkage to leadership among youth populations. Additionally, the second phase of the present study identified only academic PsyCap (not implicit PsyCap) as a significant predictor of self-perceived leadership skills among the surveyed youth, thus indicating a methodological consideration for how PsyCap should perhaps be measured in youth populations.

The YLLSDS (Seevers, Dormody, \& Clason, 1995) serves as a useful measure of leadership skills among youth populations; however, it has not been tested for its psychometric properties through the use of analytic methods such as exploratory and confirmatory factor analyses. The combined results of the present study along with the results of McElravy and Hastings (2014) study perhaps serve as useful preliminary data in the pursuit of developing a psychometrically sound measure of youth leadership, as potential items related to empathy, emotional intelligence, and psychological capital will likely provide initial construct validity.

Implications for Leadership Development Practice. The more developmental nature of cognitive empathy and PsyCap is an important practical consideration, as cognitive empathy and PsyCap can be reasonably impacted through youth leadership development programs whereas traitbased constructs are less likely to be impacted from training and development activities. Cognitive empathy relates to understanding the emotions of another (Joliffe \& Farrington, 2006); thus, youth leadership development programming focused on empathy-building activities such as active listening (see Fritz, 2004 or Hoppe, 2006) may prove to be useful. PsyCap is comprised of four lower-order constructs, namely hope, efficacy, resiliency, and optimism (Luthans, Youssef, \& Avolio, 2007). Youth leadership development programming may find value in incorporating PsyCap micro-interventions modeled after Luthans, Avey, Avolio, Norman, and Combs (2006) and/or Luthans, Avey, Avolio, and Peterson (2010). For example, the micro-intervention around hope in Luthans et al. (2010) could be modified for a youth population by having students generate personally valuable, challenging, and timebounded school-, family-, and/or community-related goals. Next, youth participants could formulate multiple pathways to reach the goals and identify obstacles. Each youth participant could then receive peer feedback regarding additional pathways and expected obstacles.

Additionally, considering the predictive associations between cognitive empathy, PsyCap, and youth leadership skills, cognitive empathy and PsyCap could be useful tools in evaluating the impact of leadership development training efforts in youth populations. For example, existing youth leadership development programs may find value in measuring changes in cognitive empathy and positive psychological capacity (using a pre-post, post-then-pre, or multiple-timepoint measurement format) as those changes may serve as a helpful proxy in documenting leadership development value. 
Limitations and Future Research. While cognitive empathy emerged as a significant predictor of youth leadership life skills in the first phase, cognitive empathy did not demonstrate a significant association with self-perceived leadership skills among youth surveyed in the second phase. Additionally, the implicit measure of PsyCap did not demonstrate a significant association with self-perceived leadership skills among youth surveyed in the first phase, but the academic PsyCap measure emerged as a significant predictor of youth leadership life skills in the second phase. Taking these inconsistencies along with generally small sample sizes and pre-selection of student participants on the basis of demonstrated leadership potential, repeating these studies among broader youth populations will be important to provide more conclusive results. Additionally, the non-experimental design further limits the connection from the data to the population. To address this limitation, future research may need to consider alternative quantitative methodological designs and/or include the collection of qualitative data to triangulate the quantitative results. Specifically, future leadership research on youth populations will benefit from longitudinal examination on the extent to which skills developed in youth leadership development programming translates to leadership effectiveness as adults.

Considering all the administered measures were selfreport, the potential for common-method variance is an inherent limitation. To address this limitation in the present study, student participants completed the measures for the predictor and criterion variables on different days as recommended by Podsakoff et al. (2003). To further address this limitation in future research, researchers may want to consider administering both self- and other-rated assessments so as to reduce common source rater effects.

\section{Conclusion}

Recall that the present study follows McElravy and Hastings' (2014) study, which identified trait-based emotional intelligence as a significant predictor of youth-leadership life skills. The results of all three combined studies suggest that youth who (a) understand others' emotions, (b) demonstrate an innate capacity to marshal their emotions and the emotions of others, and (c) generate the developmental state of high efficacy, hope, resiliency, and optimism tend to rate themselves as having higher leadership skills. Understanding these nuanced trait, skill, and behavioral leadership associations among younger generations of leaders allows leadership scholars and practitioners to more accurately predict and plan for the leadership transfer landscape over the next two decades. Additionally, understanding self-perception of leadership in youth is critical as it provides a window into leadership identity, which demonstrates a strong connection with leadership effectiveness (Avolio \& Hannah, 2008). These combined results also serve as helpful considerations for youth leadership practitioners as program outcomes, learning objectives, and activities targeting the development of cognitive empathy and PsyCap will perhaps allow for more productive leadership development efforts and better documentation of their impact. Graduates of such youth leadership development efforts, when asked to assume early career leadership roles as young adults, will perhaps be better prepared to demonstrate leadership effectiveness in a leadership transfer environment. 


\section{References}

Ang, R. P., \& Goh, D. H. (2010). Cyberbullying among adolescents: The role of affective and cognitive empathy, and gender. Child Psychiatry and Human Development, 41, 387 - 397. https://doi.org/10.1007/ s10578-010-0176-3.

Avey, J. B., Avolio, B. J., \& Luthans, F. (2011). Experimentally analyzing the impact of leader positivity on follower positivity and performance. Leadership Quarterly, 22(2), 282-294.

Avey, J. B., Reichard, R. J., Luthans, F., \& Mhatre, K. H. (2011). Meta-analysis of the impact of positive psychological capital on employee attitudes, behaviors, and performance. Human Resource Development Quarterly, 22(2), 127-152. https://doi.org/10.1002/hrdq.20070

Avolio, B. J., \& Hannah, S. T. (2008). Developmental readiness: Accelerating leader development. Consulting Psychology Journal, 60, 331-347. https://doi.org/10.1037/1065-9293.60.4.331

Bandura, A. (2006). Guide for creating self-efficacy scales. In F. Pajares, T. Urdan (Eds.), Self-efficacy beliefs of adolescents. (pp. 307-338). Greenwich, CT: Information Age Publishing.

Barbuto Jr, J. E. (1997). A critique of the Myers-Briggs Type Indicator and its operationalization of Carl Jung's psychological types. Psychological Reports, 80(2), 611-625. https://doi.org/10.2466/pr0.1997.80.2.611

Barratt, W. (2012). The Barratt Simplified Measure of Social Status (BSMSS) measuing SES. Retrieved from http://socialclassoncampus.blogspot.com/2012/06/barratt-simplified-measure-of-social.html.

Benet-Martinez, V., \& John, O. P. (1998). Los cinco grandes across cultures and ethnic groups: Multitrait multimethod analyses of the big five in Spanish and English. Journal of Personality and Social Psychology, $75,729-750$.

Boyle, G. J. (1995). Myers-Briggs Type Indicator (MBTI): Some Psychometric Limitations. Australian Psychologist, 30(1), 71-74. https://doi.org/10.1111/j.1742-9544.1995.tb01750.x

Center for Applied Rural Innovation. (2012). Community well-being in nonmetropolitan Nebraska. Nebraska Rural Poll. Retrieved from http://ruralpoll.unl.edu.

Chow, C. M., Ruhl, H., \& Buhrmester, D. (2013). The mediating role of interpersonal competence between adolescents' empathy and friendship quality: A dyadic approach. Journal of Adolescence, 36, 191 - 200.

Clapp-Smith, R. O., Vogelgesang, G., \& Avey, J. B. (2009). Authentic leadership and positive psychological capital: The mediating role of trust at the meso-level of analysis. Journal of Leadership and Organization Studies, 15, 227-240.

Cooper, R. K., \& Sawaf, A. (1997). Executive EQ: Emotional intelligence in leadership and organizations. New York, NY: Grosset/Putman.

Costa, P. T., \& McCrae, R. R. (1992). Revised NEO Personality Inventory (NEO PI-R) and NEO Five-Factor Inventory (NEO-FFI) professional manual. Odessa, FL: Pscychological Assessment Resources.

Darst, K. V. (1998). The Myers-Briggs type of college student leaders: A comparison of a residential and a commuter campus. (Doctoral dissertation). Retrieved from ProQuest Dissertations \& Theses A\&I. (304420617) 


\section{References}

Dollwet, M., \& Reichard, R. (2014). Assessing cross-cultural skills: Validation of a new measure of crosscultural psychological capital. The International Journal of Human Resource Management, 25(12), 16691696. https://doi.org/10.1080/09585192.2013.845239

Flemming, E. G. (1935). A factor analysis of the personality of high school leaders. Journal of Applied Psychology, 5, 596 - 605. https://doi.org/10.1037/h0052228

Frederickson, N., Petrides, K. V., \& Simmonds, E. (2012). Trait emotional intelligence as a predictor of socioemotional outcomes in early adolescence. Journal of Personality and Individual Differences, 52(3), 323-328. https://doi.org/10.1016/j.paid.2011.10.034

Fritz, S. (Ed.). (2004). Interpersonal skills for leadership (2nd ed.). Upper Saddle River, NJ: Prentice Hall.

Gardner, W. L., Avolio, B. J., Luthans, F., May, D. R., \& Walumbwa, F. (2005). “Can you see the real me?" A selfbased model of authentic leader and follower development. Leadership Quarterly, 16, 343-372.

Gardner, W. L., \& Martinko, M. J. (1996). Using the Myers-Briggs Type Indicator to study managers: A literature review and research agenda. Journal of Management, 22(1), 45-83. https://doi. org/10.1177/014920639602200103

George, E. I., \& Abraham, P. A. (1966). A comparative study of leaders and non-leaders among pupils in secondary schools. Journal of Psychological Researchers, 10, 116 - 120.

Goldberg, L. R. (1992). The development of markers for the big-five factor structure. Psychological Assessment, 4, 26-42. https://doi.org/10.1037/1040-3590.4.1.26

Gooty, J., Connelly, S., Griffith, J., \& Gupta, A. (2010). Leadership, affect, and emotions: A state of the science review. Leadership Quarterly, 21, 979 - 1004. https://doi.org/10.1016/j.leaqua.2010.10.005

Harms, P. D., \& Credé, M. (2010). Emotional intelligence and transformational and transactional leadership: A meta-analysis. Journal of Leadership and Organizational Studies, 17(1), 5 - 17. https://doi. org/10.1177/1548051809350894

Harms, P. D., Krasikova, D. V., \& Luthans, F. (2018). Not Me, But Reflects Me: Validating a Simple Implicit Measure of Psychological Capital. Journal of Personality Assessment, 100(5), 1 - 12. https://doi.org/10.108 0/00223891.2018.1480489

Harms, P. D., \& Luthans, F. (2012). Measuring implicit psychological constructs in organizational behavior: An example using psychological capital. Journal of Organizational Behavior, 33(4), 589-594. https://doi. org/10.1002/job.1785

Hollingshead, A. B. (1957). Two factor index of social position, Unpublished manuscript, Department of Sociology, Yale University, New Haven, CT.

Hollingshead, A. B. (1975). Four factor index of social position, Unpublished manuscript, Department of Sociology, Yale University, New Haven, CT.

Hoppe, M. H. (2006). Active listening: Improve your ability to listen and lead. Greensboro, NC: Center for Creative Leadership. 


\section{References}

Hunter, E. C., \& Jordan, A. M. (1939). An analysis of qualities associated with leadership among college students. Journal of Educational Psychology, 30, 497 - 509. https://doi.org/10.1037/h0059722

John, O. P., Donahue, E. M., \& Kentle, R. L. (1991). The Big Five Inventory-Versions 4a and 54. Berkley, CA: University of California Berkeley, Institute of Personality and Social Research. https://doi.org/10.1037/ t07550-000

John, O. P., Naumann, L. P., \& Soto, C. J. (2008). Paradigm shift to the integrative big-five trait taxonomy: History, measurement, and conceptual issues. In O. P. John, R. W. Robins, \& L. A. Pervin (Eds.), Handbook on personality: Theory and research (pp. 114-158). New York, NY: Guilford Press.

Jolliffe, D., \& Farrington, D. P. (2006). Development and validation of the Basic Empathy Scale. Journal of Adolescence, 29(4), 589-611. https://doi.org/10.1016/j.adolescence.2005.08.010

Jolliffe, D., \& Farrington, D. P. (2011). Is low empathy related to bullying after controlling for individual and social background variables? Journal of Adolescence, 34, $59-71$.

Joseph, D. L., Jin, J., Newman, D. A., \& O'Boyle, E. H. (2015). Why does self-reported emotional intelligence predict job performance: A meta-analytic investigation of mixed El. Journal of Applied Psychology, 100(2), $298-342$.

Joseph, D. L., \& Newman, D. A. (2010). Emotional intelligence: An integrative meta-analysis and cascading model. Journal of Applied Psychology, 95(1), 54 - 78. https://doi.org/10.1037/a0017286

Judge, T. A., Bono, J. E., Ilies, R., Gerhardt, M.W. (2002). Personality and leadership: A qualitative and quantitative review. Journal of Applied Psychology, 87(4), 765 - 780. https://doi.org/10.1037/00219010.87.4.765

Jung, C. G. (1971). Psychological types. Princeton, NJ: Princeton University Press.

Karnes, F. A., \& D'llio, V. R. (1990). Correlations between personality and leadership concepts and skills as measured by the High School Personality Questionnaire and the Leadership Skills Inventory. Psychological Reports, 66, 851 - 856. https://doi.org/10.2466/pr0.1990.66.3.851

Karnes, F. A., \& McGinnis, J. C. (1996). Scores on indicators of leadership skills, locus of control, and selfactualization for student leaders in grades 6 to 10. Psychological Reports, 78, 1235 - 1240. https://doi. org/10.2466/pr0.1996.78.3c.1235

Kellett, J. B., Humphrey, R. H., \& Sleeth, R. G. (2002). Empathy and complex task performance: Two routes to leadership. Leadership Quarterly, 13(5), 523- 544.

Kellett, J. B., Humphrey, R. H., \& Sleeth, R. G. (2006). Empathy and the emergence of task and relations leaders. Leadership Quarterly, 17(2), $146-162$.

Kureshi, A., \& Fatima, B. (1984). Power motive among student leaders and non-leaders: Testing the affectivearousal model. Journal of Psychological Researches, 28, 21 - 24.

Landau, E., \& Weissler, K. (1990). Tracing leadership in gifted children. Journal of Psychology, 125, 681- 688. https://doi.org/10.1080/00223980.1991.10543331 


\section{References}

Lord, R. G., Hall, R. J., \& Halpin, S. M. (2011). Leadership skill development and divergence: A model for the early effects of gender and race on leadership development. In S. E. Murphy \& R. J. Reichard (Eds.), Early development and leadership (pp. 229-252). New York, NY: Routledge.

Luthans, F. (2011). Organizational behavior: An evidence-based approach (12th ed.). New York, NY: McGrawHill.

Luthans, F., Avey, J. B., Avolio, B. J., Norman, S. M., \& Combs, G. J. (2006). Psychological capital development: Toward a micro-intervention. Journal of Organizational Behavior, 27, 387-393. https://doi.org/10.1002/ job.373

Luthans, F., Avey, J. B., Avolio, B. J., \& Peterson, S. J. (2010). The development and resulting performance impact of positive psychological capital. Human Resource Development Quarterly, 21(1), 41-67. https:// doi.org/10.1002/hrdq.20034

Luthans, F., Avey, J. B., \& Patera, J. L. (2008). Experimental analysis of a web-based training intervention to develop positive psychological capital. Academy of Management Learning \& Education, 7(2), 209-221. https://doi.org/10.5465/amle.2008.32712618

Luthans, B. C., Luthans, K. W., \& Avey, J. B. (2014). Building the leaders of tomorrow: The development of academic psychological capital. Journal of Leadership \& Organizational Studies, 21(2), 191-199. https:// doi.org/10.1177/1548051813517003

Luthans, B. C., Luthans, K. W., \& Jensen, S. (2012). The impact of business school students' psychological capital on academic performance. Journal of Education for Business, 87, 253-259. https://doi.org/10.1080 /08832323.2011.609844

Luthans, F., Youssef, C. M., \& Avolio, B. J. (2007). Psychological capital: Developing the human competitive edge. Oxford, UK: Oxford University Press.

Mavroveli, S., Petrides, K. V., Shove, C., \& Whitehead, A. (2008). Investigation of the construct of trait emotional intelligence in children. Journal of European Child and Adolescent Psychiatry, 17(8), 516 - 526. https://doi.org/10.1007/s00787-008-0696-6

McCrae, R. R., \& Costa Jr, P.T. (1989). Reinterpreting the Myers-Briggs type indicator from the perspective of the five-factor model of personality. Journal of Personality, 57(1), 17-40. https://doi. org/10.1111/j.1467-6494.1989.tb00759.x

McCullough, P. M., Ashbridge, D., \& Pegg, R. (1994). The effect of self-esteem, family structure, locus of control, and career goals on adolescent leadership behavior. Journal of Adolescence, 29, $605-611$.

McElravy, L. J., \& Hastings, L. J. (2014). Profiling the youth leader: Personality and emotional intelligence trends and their relationship to leadership skills. Journal of Agricultural Education, 55(1), 134 - 151.

Moore, L. L., \& Rudd, R. D. (2004). Leadership skills and competencies for extension directors and administrators. Journal of Agricultural Education, 45(3), 22 - 33. https://doi.org/10.5032/jae.2004.03022

Moore, L. L., \& Rudd, R. D. (2005). Extension leaders' self-evaluation of leadership skills areas. Journal of Agricultural Education, 46(1), 68 - 78. https://doi.org/10.5032/jae.2005.01068 


\section{References}

Murphy, S. E., \& Johnson, S. K. (2011). The benefits of a long-lens approach to leader development: Understanding the seeds of leadership. Leadership Quarterly, 22, 459-470.

Nunnally, J. C. (1978). Psychometric theory (2nd ed.). New York: McGraw-Hill.

O'Boyle, E. H., Humphrey, R. H., Pollack, J. M., Hawver, T. H., \& Story, P. A. (2011). The relation between emotional intelligence and job performance: A meta-analysis. Journal of Organizational Behavior, 32(5), 788-818. https://doi.org/10.1002/job.714

Owings, J. A., \& Nelson, C. L. (1979). FFA leaders and personality traits. Journal of Agricultural Education, $20(1), 40-44$.

Petrides, K. V., \& Furnham, A. (2006). The role of trait emotional intelligence in a gender-specific model of organizational variables. Journal of Applied Social Psychology, 36(2), 552-569. https://doi.org/10.1111/ j.0021-9029.2006.00019.x

Petrides, K. V., Sangareau, Y., Furnham, A., \& Frederickson, N. (2006). Trait emotional intelligence and children's peer relations at school. Journal of Social Development, 15(3), 537 - 547. https://doi. org/10.1111/j.1467-9507.2006.00355.x

Pitichat, T., Reichard, R. J., Kea-Edwards, A., Middleton, E., \& Norman, S. M. (2018). Psychological capital for leader development. Journal of Leadership \& Organizational Studies, 25(1), 47-62. https://doi. org/10.1177/1548051817719232

Pittenger, D. J. (2005). Cautionary comments regarding the Myers-Briggs Type Indicator. Consulting Psychology Journal: Practice and Research, 57(3), 210 - 221. https://doi.org/10.1037/1065-9293.57.3.210

Podsakoff, P. M., MacKenzie, S. B., Lee, J. Y., \& Podsakoff, N. P. (2003). Common method biases in behavioral research: A critical review of the literature and recommended remedies. Journal of Applied Psychology, 88(5), 879 - 903. https://doi.org/10.1037/0021-9010.88.5.879

Quoidbach, J., \& Hansenne, M. (2009). The impact of trait emotional intelligence on nursing team performance and cohesiveness. Journal of Professional Nursing, 25(1), 23-29. https://doi.org/10.1016/j. profnurs.2007.12.002

Reichard, R. J., \& Paik, S. J. (2011). Developing the next generation of leaders: Research, policy, and practice. In S. E. Murphy \& R. J. Reichard (Eds.), Early development and leadership (pp. 309-328). New York, NY: Routledge.

Rego, A., Sousa, F., Marques, C., \& Cunha, M. P. e. (2012). Authentic leadership promoting employees' psychological capital and creativity. Journal of Business Research, 65, 429-437. https://doi.org/10.1016/j. jbusres.2011.10.003

Roberts, W., \& Strayer, J. (1996). Empathy, emotional expressiveness, and prosocial behavior. Child Development, 67(2), 449-470. https://doi.org/10.2307/1131826

Rosete, D., \& Ciarrochi, J. (2005). Emotional intelligence and its relationship to workplace performance outcomes of leadership effectiveness. Leadership \& Organization Development, 26(5), 388-399. https:// doi.org/10.1108/01437730510607871 


\section{References}

Salovey, P., \& Mayer, J. D. (1990). Emotional intelligence. Imagination, Cognition and Personality, 9(3), 185211. https://doi.org/10.2190/DUGG-P24E-52WK-6CDG

Saucier, G. (1994). Mini-markers: A brief version of Goldberg's unipolar big-five markers. Journal of Personality Assessment, 63, 506-516. https://doi.org/10.1207/s15327752jpa6303_8

Seevers, B., \& Dormody, T. J. (1994). Predicting youth life leadership skills development among senior 4-H members. Journal of Agricultural Education, 35(3), $64-69$.

Seevers, B. S., Dormody, T. J., \& Clason, D. L. (1995). Developing a scale to research and evaluate youth leadership life skills development. Journal of Agricultural Education, 36(2), 28-34. https://doi.org/10.5032/ jae.1995.02028

Sinha, D., \& Kumar, P. (1966). A study of certain personality variables in student leadership. Psychological Studies, $11,1-8$.

Smith, T. A., Genry, L. S., \& Ketring, S. A. (2005). Evaluating a youth leadership life skills development program. Journal of Extension, 43(2).

Soto, C. J., John, O. P., Gosling, S. D., \& Potter, J. (2008). The developmental psychometrics of big five selfreports: Acquiescence, factor structure, coherence, and differentiation from ages 10 to 20. Journal of Personality and Social Psychology, 94(4), 718-737. https://doi.org/10.1037/0022-3514.94.4.718

Soto, C. J., John, O. P., Gosling, S. D., \& Potter, J. (2011). Age differences in personality traits from 10 to 65: Big five domains and facets in large cross-sectional sample. Journal of Personality and Social Psychology, $100(2), 330-348$.

Sy, T. T., Tram, S., \& O'Hara, L. A. (2006). Relation of employee and manager emotional intelligence to job satisfaction and performance. Journal of Vocational Behavior, 68, 461-473. https://doi.org/10.1016/j. jvb.2005.10.003

U.S. Bureau of Labor Statistics. (2017). Current population survey. Retrieved from: https://www.bls.gov/cps/ cpsaat11b.htm.

van der Linden, D., Pekaar, K. A., Bakker, A. B., Schermer, J. A., Vernon, P. A., Dunkel, C. S., \& Petrides, K. V. (2017). Overlap between the general factor of personality and emotional intelligence: A meta-analysis. Psychological Bulletin, 143(1), 36 - 52. https://doi.org/10.1037/bul0000078

Van Linden, J. A., \& Fertman, C. I. (1998). Youth leadership: A guide to understanding leadership development in adolescents. San Francisco, CA: Jossey-Bass.

Van Rooy, D. L., \& Viswesvaran, C. (2004). Emotional intelligence: A meta-analytic investigation of predictive validity and nomological net. Vocational Behavior, 65, 71-95. https://doi.org/10.1016/S00018791(03)00076-9

Wingenbach, G. J. (2000). Personality types and final grades in group organization and leadership development. Proceedings of the 27th Annual National Agricultural Education Research Conference, (pp. $69-80)$. 


\section{References}

Wolff, S. B., Pescosolido, A. T., \& Druskat, V. U. (2002). Emotional intelligence as the basis of leadership emergence in self-managing teams. Leadership Quarterly, 13(5), 505- 522.

Yukl, G. (2010). Leadership in organizations (7th ed.). Upper Saddle River, NJ: Prentice Hall. 